BBR 01452

\title{
A microdialysis study of ventral striatal dopamine during sexual behavior in female Syrian hamsters
}

\author{
Robert L. Meisel ${ }^{a}$, Dianne M. Camp ${ }^{b}$ and Terry E. Robinson ${ }^{b}$

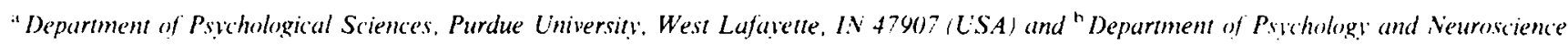 \\ Program. The Liniversity of Michigan. Anm Arhor. MI 48109 (LSA)
}

(Received 30 July 1992)

(Revised version received 20 September 1992)

(Accepted 25 February: 1993)

Key words: Microdialysis; Nucleus accumbens; Sexual behavior; Dopamine; Dihydroxyphenylacetic acid; Homovanillic acid; 5-Hydroxyindole acetic acid; Female hanster

\begin{abstract}
Microdialysis was used to study the effects of exposure to a male hamster on extracellular concentrations of dopamine. dihydroxyphenylacetic acid (DOPAC), homovanillic acid (HVA), and 5-hydroxyindole acetic acid (5-HIAA) in the ventral striatun of ovariectomized female Syrian hamsters pretreated with either estradiol and progesterone, or a similar regimen of oil injections. The hormone-treated females showed high levels of lordosis throughout the hour of exposure to the male. In hormone-treated females. there was a rapid elevation of dialysate dopamine within the first $15 \mathrm{~min}$ of exposure to the male. Dialysate dopamine gradually declined over the next 45 min. though remaining significantly above baseline during the entire period of exposure to the male. None of the oil-treated females showed any indication of lordosis, and the addition of the male produced only a small increase in dopamine at $30 \mathrm{~min}$, after which dopamine returned to pre-male basal levels. DOPAC, HVA. and 5-HIAA were all elevated following introduction of the male for both groups of fenales. These results suggest that ovarian hormones modulate the responsivity of ventral striatal dopamine to incentive stimuli associated with mating behavior in females, although extracellular levels of dopamine in the ventral striatum do not seen to be directly coupled to the display of lordosis.
\end{abstract}

\section{INTRODL:CTION}

Gordon Mogenson was one of the first to suggest that dopaminergic inputs to the nucleus accumbens from the ventral tegmentum play a fundamental role in allowing animals to gate neural information specifying the animal's motivational state into an appropriate behavioral output ${ }^{7.21 .25}$. Recent microdialysis and voltammetry studies of sexually experienced male rats are consistent with the proposition that nucleus accumbens dopamine regulates the expression of this motivated behavior. Generally, these studies found that extracellular dopamine levels increase in the nucleus accumbens during copulation, or even following exposure of male rats to cues, such as the mating chamber, previously associated with an estrous female rat ${ }^{5,17,18,20,22,23}$. The prevailing interpretation was that the incentive motivational properties of mating itself, or the associative reward properties of the testing chamber, stimulate nu-

Correspondence: R.I. Meisel, Department of Psychological Sciences, Purdue Lniversity. West Lafayette, IN 47907-1364, USA. clcus accumbens dopamine release. A problem with this interpretation, however, is that anticipatory sexual behavior and copulation in male rats involves a high degree of locomotor activity. It can be difficult, therefore, to ascertain whether an increase in nucleus accumbens dopamine in these situations is related specifically to the activation of sexual behavior, or more generally to increases in voluntary motor activity.

The sexual behavior of female Syrian hamsters has characteristics that could prove advantageous in addressing questions about the role of nucleus accumbens dopamine in the regulation of sexual behavior in particular, and perhaps motivated behaviors in general. Like males, sexual behavior in most female rodents involves high levels of locomotor activity. But female Syrian hamsters are an exception to this rule. Female hamsters maintain an immobile lordosis posture for most of the time during mating. For example, receptive female hamsters may hold the lordosis posture on average for $9.5 \mathrm{~min}$ of a 10 -min test ${ }^{4}$, and female hamsters housed with males may have total lordosis durations of over $50 \mathrm{~min}$ of approximately a $9($ )-min receptive por- 
tion of their estrous cycle ${ }^{16}$. Sexual behavior in female hamsters may provide, therefore. a unique opportunity to study neurochemical changes accompanying a motivated behavior unconfounded by increases in general locomotor activity. Since microdialysis provides an opportunity to correlate neurochemical changes with ongoing spontaneous behavior, we used this technique as an initial attempt to study the relationship between extracellular dopamine and female sexual behavior in $\mathrm{Syr}$ ian hamsters.

\section{MATERIALS AND MFTHODS}

\section{Subjects:}

Subjects were 13 adult female Syrian hamsters, 60) days old upon arrival from Charles River Laboratories (Kingston, NY). Adult male Syrian hamsters were used as stimulus males during the behavioral tests. Female hamsters were housed initially in groups of 3-4 in plastic cages $(46 \times 24 \times 20 \mathrm{~cm})$. The colony room was maintained with lights on at $6.00 \mathrm{a} . \mathrm{m}$. and off at 8.00 p.m. and at a temperature of $72^{\circ} \mathrm{C}$. Food and water were freely available throughout the experiment.

\section{Surgery}

One week after arrival the female hamsters were bilaterally ovariectomized using sodium pentobarbital anesthesia $(7.5 \mathrm{mg} / 100 \mathrm{~g} \mathrm{~b}$. wt.). Following the ovariectomy a unilateral stainless steel guide cannula (21 ga. thin wall tubing) was implanted stereotaxically 1.0 $\mathrm{mm}$ below the dural surface overlying the nucleus accumbens. The guide cannula was affixed in place with dental acrylic applied to the cannula and skull screws. In addition, an elbow of $15 \mathrm{ga}$. stainless steel tubing was cemented to the caudal skull surface near lambda. and this was used later to tether the female to a liquid swivel during collection of dialysis samples. A stainless steel stylet was inserted into the guide cannula to keep it patent until insertion of the dialysis probe.

\section{Probe design}

A modification of the removable, concentric dialysis probe described previously ${ }^{27}$ was used. For these probes an $8 \mathrm{~mm}$ collar of $21 \mathrm{ga}$. thin wall stainless steel tubing was cemented over a $17 \mathrm{~mm}$ length of 25 ga. stainless steel tubing such that the bottom $8 \mathrm{~mm}$ of the $25 \mathrm{ga}$. tubing was exposed. A $12.5 \mathrm{~mm}$ piece of hollow regenerated cellulose dialysis fiber with a $6,000 \mathrm{Da}$ mol. wt. cutoff $(250 \mu \mathrm{m}$ outside diameter, Spectrum Medical Industries, Los Angeles, CA) was inserted $6 \mathrm{~mm}$ into the bottom of the $25 \mathrm{ga}$. tubing and secured with epoxy cement. The end of the dialysis fiber was then plugged with epoxy. The inlet tubing was a length of fused silica tubing ( $75 \mu \mathrm{m}$ i.d. $\times 150 \mu \mathrm{m}$ o.d. Polymicro Technologies, Phoenix, AZ) inserted into the dialysis fiber to within $0.5 \mathrm{~mm}$ of the epoxy plug. The outlet tubing was a larger diameter fused silica tube $(100) \mu \mathrm{m}$ i.d. $\times 170 \mu \mathrm{m}$ o.d.) inserted into the 25 gid. stainless steel tubing about $3-4 \mathrm{~mm}$ above the opening of the dialysis fiber. The fused silica tubing was protected with a sheath of plastic tubing. Finally, the exposed dialysis membrane was coated with cyanoacrylic cement learing only $2 \mathrm{~mm}$ of exposed membrane at the tip.

\section{In vitro probe recovery and HPL.C analisis}

The dialysis probes were tested in vitro at room temperature for their efficiency in recovering dopamine, the acid metabolites of dopamine (DOPAC and HVA). and 5-HIAA, a metabolite of serotonin. The efficiencies of the probes for recovering dopanine ranged only from 13.9-16.9" ${ }^{\prime \prime}$, and therefore, the values reported are not corrected for probe recover!

The HPLC system was previously described by Robinson and Camp ${ }^{27}$. Briefly, the system utilized a Kontron HPLC autosampler (Model 465) coupled to a Spheri-5 RP-18 $5 \mu$ m chromatography column (Applied Biosystems) maintained at a constant temperature of $35-400^{\circ} \mathrm{C}$. Flectrochemical detection was accomplished using an ESA Coulchem II detector and an on-line computer-based data acquisition system (EZ. Chrom, Scientific Software. Inc., San Ramon, CA). Concentrations of dopamine and the metabolites were calibrated from standards based on analyses of peak heights.

\section{Behavioral testing and sample collection}

One week following surgery. female hamsters were injected with either $10 \mu \mathrm{g}$ estradiol benzoate in $0.1 \mathrm{ml}$ cottonseed oil $(n=7)$ or $0.1 \mathrm{ml}$ of cottonseed oil $(n=6)$ on 2 consecutive days. After the second injection, each female was anesthetized with ether and a dialysis probe was inserted into the intracranial guide cannula. The female was placed in an oval Plexiglas testing chamber $(48 \times 30 \times 28.5 \mathrm{~cm})$. Suspended over the test chamber was a single channel liquid swivel to which the inlet tubing of the dialysis probe was connected. A $42-\mathrm{cm}$ length of braided model airplane control cable linked the swivel to the $15 \mathrm{ga}$. stainless steel tubing on the caudal surface of the female's skull. The outlet from the dialysis probe was inserted into a collection vial that was attached to the cable. After insertion of the dialysis probe, a Ringer's solution $(145 \mathrm{mM} \mathrm{NaCl}, 2.7 \mathrm{mM}$ $\mathrm{KCl}, 1.2 \mathrm{mM} \mathrm{CaCl}, 1.0 \mathrm{mM} \mathrm{MgCl}, 0.2 \mathrm{mM}$ ascorbic acid, $\mathbf{p H}=7.30$ ) was flushed through the probe at at rate of $1.5 \mu \mathrm{l} / \mathrm{min}$ for about $1 \mathrm{~h}$, after which the rate was lowered to $0.3 \mu \mathrm{l} / \mathrm{min}$. 
The next day the pump wals turned back up to 1.5 $\mu 1$ :min and the probes were flushed with Ringer's at this rate for at least $1 \mathrm{~h}$, after which 15 min samples were collected for $1 \mathrm{~h}$. Females previously treated with estradiol benzoate then were injected with $0.5 \mathrm{mg}$ of progesterone in $0.1 \mathrm{ml}$ cottonseed oil and females previously given oil were again injected with $0.1 \mathrm{ml}$ of cottonseed oil. Three h later another set of four 15 -min samples were collected. After this a male Syrian hamster was placed in the testing chamber with the female and 15 -min samples were again collected for the next hour. during which time the behavior of the animals was videotaped. The males were then removed and two more 15-min samples were taken. Next, the females were injected with $0.5 \mathrm{mg}$ of $\mathrm{D}$-amphetamine sulfate (approximatcly $4 \mathrm{mg}: \mathrm{kg}$ b.wt.). and two final $15-\mathrm{min}$ samples collected.

After collection of the last dialysis sample, the probes were removed and the females were returned to their home cages. One to 5 days after dialysis, the females were given an overdose of sodium pentobarbital (about $15 \mathrm{mg}: 100 \mathrm{~g}$ b.wt.) and perfused intracardially with $0.9^{\circ}$ " saline followed by $4^{\prime \prime}{ }_{0}$ formaldehyde with $0.9^{\circ}{ }^{\circ}$ saline. The brains were stored in $4^{\circ}$ "formaldehyde containing 15" "sucrose until sectioned coronally and stained with Cresyl violet to determine the location of the dialysis probes.

\section{Behavioral analises}

The videotapes of the hour-long portion of each test session when a male was present were analyzed for spontaneous locomotor activity and duration of lordosis. The behavioral measures were summarized in four 15-min blocks corresponding to the timing of the dialysis samples taken. Locomotor activity was based on dividing the area of the test arena into thirds lengthwise on the video screen and counting the number of area entries. Lordosis was quantified as the time that the female assumed the lordosis posture during each 15 min block.

\section{RISSLISTS}

\section{Histological verification of probe placements}

Only data from animals whose probes were located within the boundaries of the nucleus accumbens were included in the data analyses. Six (of an initial 8) oiltreated females and 7 (of an initial 10) estrogen- and progesterone-treated females had implants distributed through the rostral to caudal extent of the nucleus accumbens. All of the 5 placements outside the nucleus accumbens were too caudal, with 4 located in the me- dial preoptic area and $l$ in the rostral bed nucleus of the stria terminalis. Of the accumbens placements, 5 probes were positioned in the nucleus accumbens medial to (accumbens shell) and 8 probes were lateral to (accumbens core) the anterior commissure. In all cases the probes spanned the dorsoventral extent of the accumbens, extending dorsally to include the ventral tip of the caudate.

\section{Locomotor activity and sexual beharior}

Behavioral and neurochemical data were analyzed initially using ANOVAs. followed where appropriate by post-hoc Newman-Keuls tests. Significance levels for all tests were set at $P<0.05$. The behavioral data are summarized in Fig. 1. Videotapes of the test sessions with the males were available for 5 of the 6 oil-treated females and all 7 hormone-treated females. There was no significant change in locomotor activity across the hour of behavioral testing for the oil-treated females, perhaps due to the marked variability in activity levels among animals. Females treated with estradiol and progesterone showed a significant decrease in locomotor activity $\left(F_{3,1 \times}=3.257, P<0.05\right)$ such that activity levels in the last 15 -min time block were significantly lower $(P<0.05)$ than in the first 15 -min time block. None of the oil-treated females showed lordosis. All of
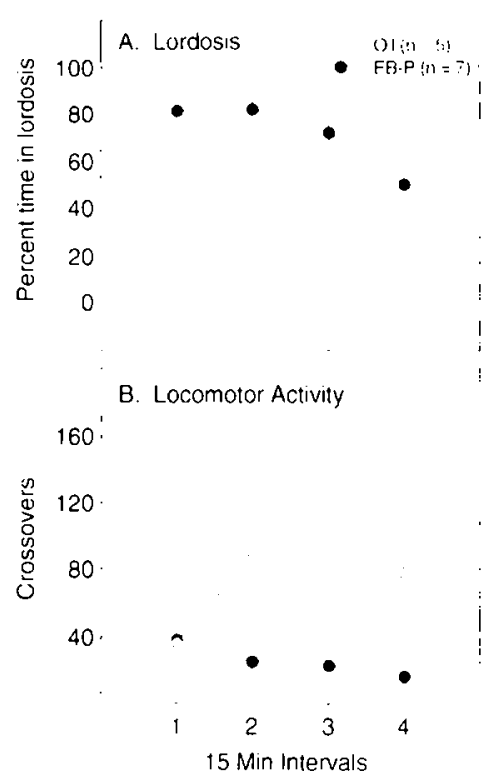

Fig. 1. Mean ( S.I.M.) percent lime in lordosis and crossovers for each 15 min time interval during the I h of exposure to the male. Only females treated with estradisl and progesterone (EB-P) showed any lordosis. and for these females the percent duration of lordosis for the last 15-min interval was significantly lower than for the the pror intervals $(P<0.05)$. In addition. there were significantly fewer crossovers for the last 15 min interval compared with the first 15 min interval $(P<0.05)$. There was no significant change in crossovers for oil-treated females. and activity levels between these females and pemales receiving I:B-P did not differ. 
the estradiol and progesterone treated females showed high levels of lordosis. The hormone-treated females spent on average about $80_{\%}^{\circ}$ of the first $30 \mathrm{~min}$ in lordosis. There was a significant decline in lordosis responding over the hour of behavioral testing $\left(F_{3.18}=4.009, P<0.03\right)$, such that the percent of time during which lordosis was maintained was significantly lower on the last 15 -min period relative to each of the three previous 15 -min periods $(P<0.05)$.

\section{Basal neurochemical levels following steroid treatment}

The first four basal samples were taken about $24 \mathrm{~h}$ after the second estradiol or oil injection. For these basal samples a hormone treatment $\times$ dialysis samples $(2 \times 4)$ ANOVA was used to examine possible effects of estradiol treatment on basal levels of dopamine and metabolites. Although the average basal levels of dopamine were somewhat higher in estradiol-treated animals, this was not statistically significant $(P>0.1)$. There was also no significant effect of estradiol treatment on the basal metabolite values.

To examine possible effects of progesterone on basal concentrations of dopamine, DOPAC. HVA, and 5-HIAA in dialysate the average of the first four basal samples was compared with the four samples taken 3 $\mathrm{h}$ after progesterone or oil injection using separate oneway ANOVAs for the estradiol-treated and oil-treated groups. Again, there were no significant changes in basal levels of any of the substances measured for either the oil-treated or hormone-treated females. The avcrage of the dopamine and metabolite levels from the basal samples following estradiol and progesterone (or oil) are presented in Fig. 2.

\section{Effects of introduction of the male}

The effect of presentation of the male on dialysatc dopamine is shown in Fig. 2. In the hormone-treated females, dopamine increased rapidly after introduction of the male $\left(F_{4.24}=12.97, P<0.0001\right)$, peaking in the first 15 -min sample, and remaining significantly elevated over the premale baseline during the 1 -h period that the male was present $(P<0.01)$. After the first $15 \mathrm{~min}$ of exposure to the male, there was a gradual decline in dopamine, with dialysis levels of dopamine in the 45and 60-min samples significantly lower than in the first 15 -min sample $(P<0.01)$. Dialysate dopamine levels were significantly lower $\left(F_{2.12}=16.981, P<0.0003\right)$ in the two samples taken after the male was removed compared with the sample taken immediately preceding removal of the male. Changes in metabolite levels are summarized in the legend to Fig. 2.

There was a different pattern of change in dopamine levels in oil-treated females $\left(F_{4.20}=3.352, P<0.03\right)$ fol-

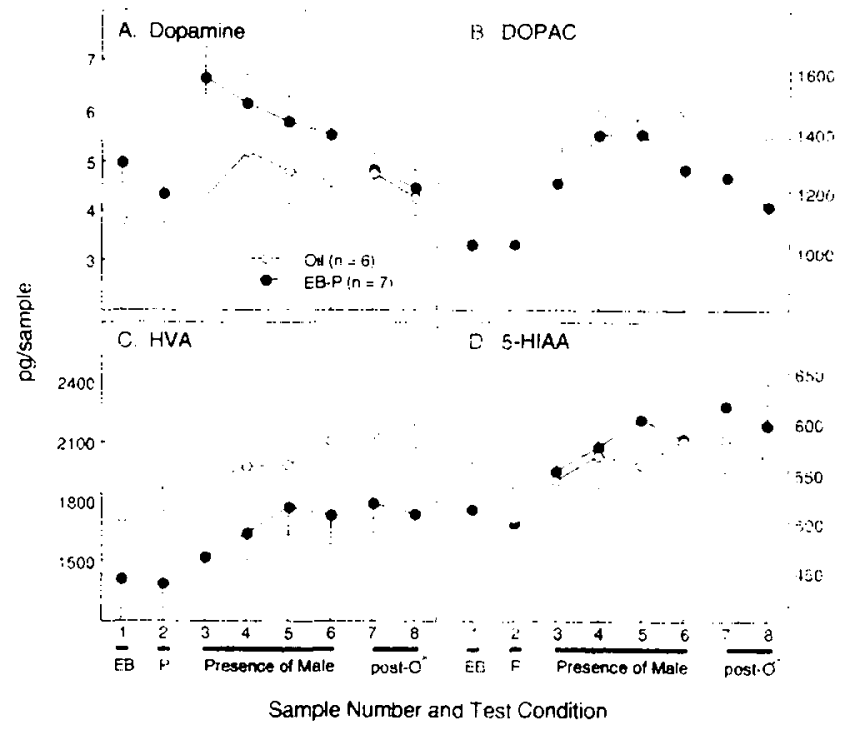

Fig. 2. Mean ( \pm S.E.M.) levels of dopamine, DOPAC. HVA, and 5-HIAA in 15-min dialysis samples taken during the presence of the male, as well as after removal of the male, compared with the air $r$ age level of the 15-min samples for each of the baseline periods. Note the dranatic increase in dialysate dopamine $(P<0.01)$ in the females treated with estradiol and progesterone (EB-P) following introduction of the male. This increase in dopamine was not observed at this time point in the oil-treated females. For hormone-treated females, levels of DOPAC, HVA, and 5-HIAA ( $F$ values $(\mathrm{d} f=4.24)$ ranged between 29.257 and $62.558 . P<0.0001)$ were all elevated above baseline during the entire $1-h$ period when the male was present. L.evels of all of these metabolites peaked at $+5 \mathrm{~min}$ after introduction of the male $(P<0.01)$, though only DOPAC significantly dectined after the male was removed $\left(F_{2,12}=11.101, P-(1.002)\right.$. For oil-ircated females. lcvels of DOPAC, HVA, and 5-HIAA $(\mathcal{H}$ values ranged between 9.120 and $14.813(\mathrm{df}=4.20), P<0.001-0.0001)$ were elevated during the male's presence, and did not signiticantly change following removal of the male.

lowing the introduction of the male. Oil-treated females showed a significant increase $(P<0.05)$ in dopamine only in the dialysate sample obtained $30 \mathrm{~min}$ after introduction of the male, relative to the average of the premale baseline samples.

\section{Effects of amphetamine administration}

To insure that dopamine release could be induced in all animals, a "challenge" injection of D-amphetamine was given at the end of the post-male sampling period (Fig. 3). Amphetamine produced its expected effects. increasing dialysis dopamine in both hormone-treated $\left(F_{3.18}=31.12, \quad P<0.0001\right)$ and oil-treated females $\left(F_{3.15}=22.409, P<0.0001\right)$, relative to the two prior basal samples $(P<0.01)$. DOPAC levels declined in both hormone-treated $\left(F_{3,1 \times}=60.907, P<0.0001\right)$ and oil-treated females $\left(F_{3,15}=27.918, P<0.0001\right)$ after $D$-amphetamine treatment. There were no significant differences in responsivity to D-amphetamine between the hormone and oil-treated females. 


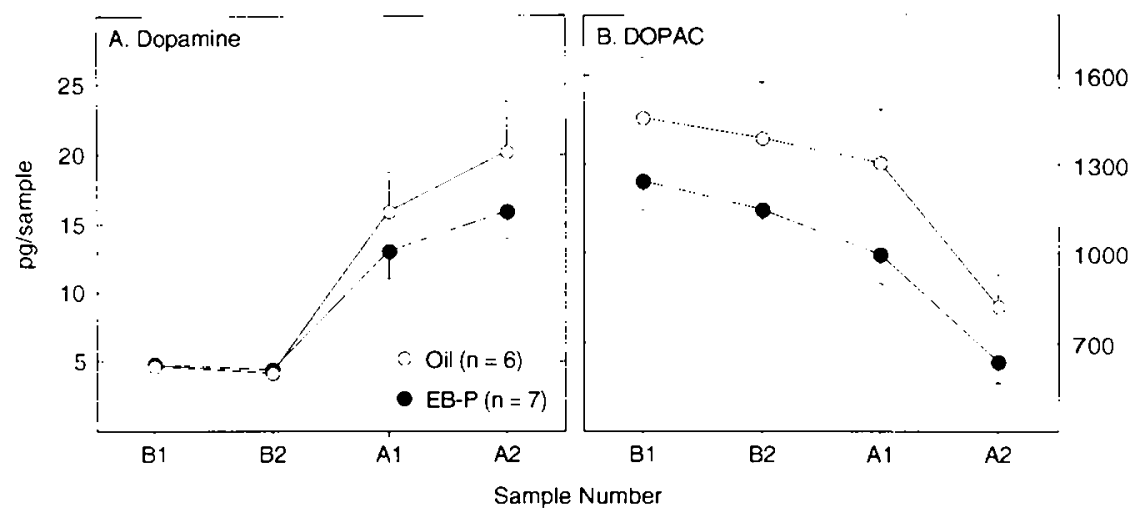

Fig. 3. Effects of D-amphetamine administration on extracellular concentrations of dopanine and DOPAC in hormone-treated (estradiol benzoate and progesterone: F:B-P) and oil-treated female hamsters. Amphetamine treatment (samples Al and A2) significantly increased dopamine levels $(P<0 .(1))$ and significantly decreased DOPAC levels $(P<0.01)$ compared with basal sanples (B1 and B2) taken prior $(0)$ amphetamine injection. There were no significant effects of hormone treatment on the responsivity of female hamsters to $D$-amphetamine

\section{DISCLSSION}

In female hamsters rendered sexually receptive by sequential treatment with estradiol and progesterone, the introduction of a male was accompanied by a rapid increase in the extracellular concentration of dopamine in the ventral striatum as estimated by in vivo microdialysis. The increase in dialysate dopamine peaked within the first 15 min after introduction of the malc. and then showed a steady decline over the remainder of the 45-min test period. During the first 45 min of the test period the females maintained constant levels of sexual behavior. spending $75-80^{\circ}{ }_{1}$ of the time immobile in the lordosis posture. Introduction of a male also increased dialysate dopamine in oil-treated female hamsters, but the effect was not as marked as in hormone-treated females, and also was delayed in time.

It is not possible from this study to determine which aspect of the female's interaction with the male was the proximal stimulus for the elevation in ventral striatal dopamine. Evidence from several sources suggests that the increase in dopamine was not coupled to the expression of lordosis itself. First, the time course of changes in dialysate dopamine differed from that of lordosis. Dopamine peaked in the first 15 min of exposure to the male, and then gradually declined over the next 45 min. In contrast. lordosis duration was maintained at a relatively constant level for the first $45 \mathrm{~min}$ of the test, only decreasing during the last $15 \mathrm{~min}$ of the 1-h test period. Second, available evidence from studies using 6-hydroxydopamine lesions to manipulate the expression of female sexual behavior suggests that ventral striatal dopamine does not regulate lordosis in rodents. For example, intraventricular administration of 6-hydroxydopamine yielding extensive striatal damage disrupts the appetitive components (e.g. hopping and darting) of sexual behavior in female rats, yet following these lesions lordosis is unaffected or even facilitated $^{3.11}$. Mesolimbic 6-hydroxydopamine lesions have minimal effects on hopping and darting in rats, and are also without effect on lordosis "I. Flectrolytic lesions of the nucleus accumbens are also without effect on either appetitive behavior or lordosis in female rats. although rejection responses to the male increase following these lesions ${ }^{24}$. It seems unlikely, therefore, that the increases in dopamine during mating in our study are related to the execution of sexual behavior.

$A$ plausible interpretation of the results of our study is that sensory stimuli from the male contributed to the rise in extracellular dopamine. In sexually experienced male rats, exposure to the mating chamber alone or to an inaccessible femalc have been shown to increase the levels of dialysate dopamine in the nucleus accumbens ${ }^{5.22}$. Indeed. Robbins et al. ${ }^{25}$ have argued that the ventral striatum is especially responsive to environmental stimuli that have acquired incentive properties though associative processes. In our study the female hamsters at the time of testing were sexually naive. Differences in the incentive value of the male for the two groups of females was a property of prior hormone exposure and not a conditioned response. If increases in ventral striatal dopamine are, in fact, due to the incentive properties of the male. then we can extend the scope of responsiveness of the ventral striatum to include unconditioned stimuli whose value varies with the animal's physiological state.

Control female hamsters treated with only the oil vehicle also showed a small, but delayed increase in dopamine relative to hormone treated females, and did not show any evidence of lordosis hehavior. Presumably, this increase in dopamine is related to different factors than in the hormone-treated females. L.ow lev- 
els of ovarian hormones are typically associated with high levels of aggression in female hamsters ${ }^{\lambda .11}$. Although aggression was kept to a minimum in the oiltreated females in this study by group housing them ${ }^{4.11}$ prior to surgery, the small rise in dopamine seen following the introduction of the male could reflect residual aggressive capacity of the oil-treated females in the presence of the males.

Amphetamine was administered in this study to insure that dopamine release could be induced pharmacologically in those cases in which the presence of the male was without effect. In all instances, D-amphetamine produced an increase in extracellular dopamine and a decrease in extracellular DOPAC levels. with minimal effect on 5-HIAA levels, which is consistent with the results of microdialysis studies in rats (c.g. ref. 27). It was surprising, however, that the dose of D-amphetamine used in this study $(0.5 \mathrm{mg}$, about 4 $\mathrm{mg} / \mathrm{kg} \mathrm{b}$.wt.) produced only a 3-4-fold increase in dialysate dopamine, because a similar dose of D-amphetamine in rats produces a much greater increase in dopamine recovered from the accumben ${ }^{2 t}$.

Another interesting feature of dopamine dynamics in the present study was the relative amount of DOPAC and HVA found in ventral striatal dialysate. In both oil-treated and hormone-treated females the basal concentration of HVA was greater than the basal concentration of DOPAC. The average ratio of DOPAC:HVA for all hamsters was about 0.7. which is much lower than the DOPAC:HVA ratio in the ventral striatum of rats (greater than 2), and somewhat lower than the ratio of about 1 for the caudate in rats ${ }^{26}$. It has been suggested that DOPAC:HVA ratios reflect regional differences in the route of dopamine metabolism ${ }^{28}$. For example, very little dopamine in the ventral striatum of the rat may be converted to 3 -methoxytyramine ${ }^{14}$. The low DOPAC:HVA ratios seen in hamsters suggests that they may metabolize dopamine more like mice, dogs. monkeys, and humans, in which striatal levels of HVA are reported to be greater than the levels of DOPAC ${ }^{1}$.

There were no effects of estradiol and progesterone treatment alone on basal levels of dopamine or any of the monoamine metabolites in the ventral striatum of female hamsters. In the dorsal striatum estradiol has effects both on the density of dopamine receptors ${ }^{12.1}$ as well as on dopamine release ${ }^{1.2}$. We are aware of only a few studies directly assessing the effects of estrogen on nucleus accumbens dopamine. In ovariectomized female rats, neither density of dopamine receptors " nor tissue dopamine concentrations $s^{6}$ are affected by estradiol treatment, although tissue concentrations of DOPAC and HVA show a transient increase $30 \mathrm{~min}$ after estradiol injection ${ }^{\circ}$. Whether our findings indicate a difference between gonadal steroid actions on rats and hansters, or a difference between the responsiveness of the dorsal and ventral striatum is not known at this time.

In conclusion. our results are the first to directly implicate ventral striatal dopamine activity in the control of female sexual behavior. Further, the results of this study are consistent with a cole for ventral striatal dopamine in motivated behaviors. Sexual beharior in female hamsters provides several unique opportunities for studying neural mechanisms involved in the regulation of motivated behaviors. First. unlike motivated behaviors such as feeding or drinking sexual behavior can be compared in naive and experienced animals to assess the relative contributions of associative and nonassociative processes. Second. Lordosis in female hamsters is a motivated behavior whose expression involves immobility. rather than overt ativity. as is more typically the case. The rise in extracellular dopamine during this period of immobility is consistent with the idea that dopamine in the ventral striatum does not necessarily play a role in regulating goal-directed locomotor activity ${ }^{21}$. but more importantly is involved in assessing the motivational significance of stimuli that are then translated into appropriate actions. Defining the precise contributions of ventral striatal dopamine to the control of female sexual behavior awaits further study.

\section{ICKNOWLI:DGEMENIS}

This research was supported by NIDA Grant 04294 (T.E.R.) and NIH Grant HD21478 (R.L.M.). We would like to thank Christine Barnard for analyzing the videotapes and Daniel Mann for assistance with the statistical analyses.

\section{REFERINNCISS}

1 Becker, J.B.. Lstrogen rapidly potentiates amphetamine-induced striatal dopamine release and rotational behavior during microdialysis. Veurosici. Lett. 118 (1990) 169-171.

2 Becker. J.B. and Ramirez. V.D. Sex differences in the amphetamine stimulated release of catecholamincs from ral striatal lissue in vitro. Brain Rex.. 204 (1981) 361-372.

3 Caggiula. A.R. Herndon. J.G.. Scankon. R.. Greenstone. D.. Bradshaw, $W$. and Sharp, D.. Dissociation of active from immobility components of sexual behavior in female rats by central (1-hydroxydopamine: implications for $C A$ involvement in sexuat hehavior and sensorimotor responsiveness, Brain Re's. 172(1979) $505-520$.

+ Carter, C.S.. Postcopulatory sexual receptivity in the femalc hamster: the rote of the ovary and the adrenal, Horm. Behar.. ? (197?) $261-26.5$. 
5 Damsma. (i.. Pfaus. J.C... Menkstern. D.. Phillips. A.G. and Fibiger. H.C. Sexual behavior increases dopamine transmission in the nucleus accumbens and striatum of male rats: comparison with novelty and locomotion, Behar. Neturosci., 106 (1992) 181191

6 Di Paolo. T., Rouillard, C and Bedard, P., 17/ -estradiol at a physiological dose acutely increases dopamine turnover in ral brain. Firr. J. Pharmacesl. 117 (1985) 197-2013.

7 Fibiger. H.C. and Phillips, A.G.. Reward, motivation, cogntion: psichohiology of mesolelencephalic dopamine systems. In F.l: Bloom and R.S. Geiger (l-ds.). Handhook of Phisiologl. Iol. IF. Intrinsic Regulatery Sistems of the Brain. Anerican Physiology Sociel. Bethesda. 1986, pp. 647-675.

8 Floody. ().R. and Pfaff. D.H. Aggressive behavior in female hamsters: the hormonal basis for fluctuations in femiale aggressiseness correlated with estruus stalte. J. (omp. Physiol. Pachol.. 91 (1977) 4t?-464.

9) (jrelk, 1).F.. Papson, B.A. Cole. J.E. and Rowe. F. A.. The influence of eaging conditions and hormone treatments on fighting in male and female hamsters. Horm. Behar., 5 (1974) 355-366.

10) Hansen, S., Harthon, (.. Wallin, F.. I.öfberg. I.. and Svensson. K.. Mesotelencephalic dopamine sustem and reproductive behatior in the female rat: effects of ventral tegmental 6-hydroxydopamine lesions on maternal and sexual responsiveness. Behar. Ve'llresci. 105 (1991) 588-598.

11 Herndon, I (i.. Caggiula. A.R. Sharp. D.. I.llis. D. and Redgate. E... Selective enhancement of the lordotic component of female sexual behavior in rats following destruction of central catecholamine-containing systems. Brain Re's. 141 (1978) 137-151.

12 Hruska. R.I. and Pitmian. K.T.. Distribution and localization of estrogen-sensitive dopamine receptors in the rat brain. J. Neuro. (hem., 34) (1982) $1+18-1+23$

1.3 Kopin. I.J.. Catecholamine metabolism: basic aspects and clinical signticance. Pharmacol. Re'v. 37 (1985) 333-364.

1+ Kuczenshi. R. and Segal. D.S.. Differential effects of amphetamme and dopamine uptake blocters (cocaine, nomifensine) on caudate and accumbens dialsate dopamine and 3-methoxyty ramine. I. Phamacol. Exp. Ther. in press.

15 I.evesque. D. and DiPaolo. P.T. Rapid conversion of high into low striatal D2-dopanme receptor agonist binding states after an acute phesiological dose of 17 heta-estradiol. Nermosci. lett.. 88 (1988) 113-11.8.

16 lisk. R.D. C Caccio. L.A. and Catanzaro, C. Mating behavior of the golden hamster under seminatural conditions, Amim. Behar. $31(198.3) 659-6060$
17 I.ouilot, A., Gonzalez-Mora, J.1... Guadalupe. I and Mas. M.. Sex-related olfactory stimuli induce a selective increase in dopamine release in the nucleus accumbens of male rats. A voltammetric study. Brain Res.. 553 (1991) 313-317.

18 Mas, M.. Gonzalez-Mora, J.L., Louilot, 1.. Solé. C. and Guadalupe. T.. Increased dopamine release in the nucleus accumbens of copulating male rats as evideneed by in vion coltammetry.

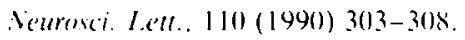

19 Meisel. R.I... Sterner. M.R and Diekman, M.A.. Differential hormonal control of aggression and sexual behavior in lemale Syrian hamsters, Homm. Behas. $22(1988)+53-466$.

20) Mitchell. J.B. and Gratton. A., Opioid modulation and sensitization of dopamine release elicited by sexually relevant stimuli: a high speed chronoamperometric study in frecty heharing rats. Brain Res. 551 (1991) 20-27.

21 Mogenson. (j.J., Jones. D. I. and Yim. ( . Y. From motiation to action: functional interface between the limbic and the motor system. Prog. Teurohiol. $1+(1980) 69-9)$ ?

22 Pfaus. J.G. Damsma. G.. Nomikos. (i. (i.. Henkstern. D.(i., Blaha. C.D. Phillips. A. $\mathbf{r}$ and Fihiger. H.C.. Sexual behavior enhances central dopamine transmission in the male rat. Brain Res. $530(1990) 345-348$.

23 Plem, I..T. Matuchik, J A. Barticld, R.I. and Auerbach. S.B.. correlation of dopamine release in the nucleus alcumbens with masculine sexual behavior in rats, Brain Res. $524(1990) 160)$. 163.

24 Rivals, F.J. and Mir, D.. Accumbens lesions in female rats increases mount rejection without modifying lordosis, Rex. Expanola fiviol. $47(190) 1) 1-6$.

25 Rohbins. T.W.. Cador. M.. Taylor, J.R. and Feretl. B.J.. I.imbic-striatal interactions in reward-related processes. Veurowi. Bishehat: Rer.. 1.3 (1989) 155-162.

26 Robinson. T. L . and (amp, D.M. I) Ines amphetamine preferenficlly increase the extracellular concentratuon of dopamine in the

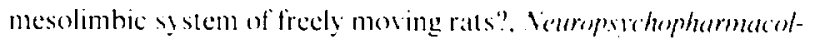
agl: $3(1990) 163 \quad 173$.

27 Robinson. T.t: and Camp. D. M., The leasibility of repeated microdialysis lor within-subjects design experiments: studies on the mesostriatal dopamine system. In T.I. Rohinson and J.B.

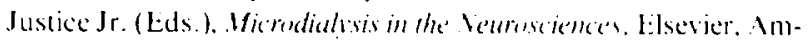
sterdam. 1991. pp. 189-234.

28 Westerink. B.H.C and Kort, J., Turnower of acid dopamine metabolites in striatal and mesolimbic tissue of the rat brain. fiur. $J$ Phamacol. 37 (1976) 249-255. 